\title{
Raf1 is a prognostic factor for progression in patients with non-small cell lung cancer after radiotherapy
}

\author{
HAO TIAN $^{1 *}$, LI YIN $^{2 *}$, KAI DING $^{2^{*}}$, YOU-YOU XIA ${ }^{3}$, XIAO-HONG WANG ${ }^{1}$, JIAN-ZHONG WU $^{3}$ and XIA HE ${ }^{2}$ \\ ${ }^{1}$ Department of Radiation Oncology, The First People's Hospital of Xinyi, Xinyi, Jiangsu 221400; \\ ${ }^{2}$ Department of Radiation Oncology, and ${ }^{3}$ Research Center of Clinical Oncology, \\ The Affiliated Jiangsu Cancer Hospital of Nanjing Medical University, Nanjing, Jiangsu 210000, P.R. China
}

Received October 5, 2017; Accepted February 13, 2018

DOI: $10.3892 /$ or.2018.6277

\begin{abstract}
Raf-1 proto-oncogene, serine/threonine kinase (Raf1) acts as a part of the RAS/RAF/MEK/ERK signaling pathway and regulates cell migration, apoptosis and differentiation. However, few studies are available on the expression and clinical significance of Raf1 in non-small cell lung cancer (NSCLC). This study investigated the clinical value and prognostic significance of Raf1 in NSCLC patients, following radiotherapy. We evaluated the Raf1 expression using immunohistochemical analyses of samples from 110 NSCLC patients who received radiotherapy. The association between Raf1 expression and clinicopathological variables was also analyzed. The multivariate Cox proportional hazard model was used to determine the prognostic value of Raf1 in regards to progression and 3-year survival. Significant associations between Raf1 expression and invasion and metastasis capability in lung cancer A549 and H1299 cell lines were identified. Results showed that $44.5 \%$ (49/110) of the NSCLC patient specimens demonstrated Raf1 expression, which was found to be positively correlated with lymph node metastasis $(\mathrm{P}=0.014)$, $\mathrm{T}$ stage $(\mathrm{P}=0.038)$ and poor histological differentiation $(\mathrm{P}=0.029)$. Later progression was observed in patients with negative or low Raf1 expression than in patients with high Raf1 expression ( $\mathrm{P}=0.002)$. The multivariate analysis indicated that Raf1 is an independent prognostic factor for time to progression (TTP) (HR, 1.94; 95\% CI, 1.16-3.25; $\mathrm{P}=0.01)$. A high Raf1 expression was found to result in a poor 3-year overall survival (OS)(HR, 1.64; 95\% CI, 0.98-2.75; $\mathrm{P}=0.06)$. Raf1 overexpression was correlated with early progression in NSCLC. Raf1 may serve as a novel prognostic factor and
\end{abstract}

Correspondence to: $\mathrm{Dr} \mathrm{Xia} \mathrm{He}$, Department of Radiation Oncology, The Affiliated Jiangsu Cancer Hospital of Nanjing Medical University, 42 Bai Zi Ting Road, Nanjing, Jiangsu 210000, P.R. China

E-mail: hexiabm@163.com

${ }^{*}$ Contributed equally

Key words: Raf1, non-small cell lung cancer, radiotherapy potential target for improving the long-term outcome of NSCLC patients.

\section{Introduction}

Lung cancer is a malignancy with high morbidity and mortality; approximately $80-85 \%$ of all lung cancers are non-small cell lung cancer (NSCLC) (1). Significant progress has been observed in NSCLC treatment, yet the 5-year survival rate of NSCLC patients is $<15 \%$ (2) and represents more than one-quarter (27\%) of all cancer deaths due to lung cancer in the US (3). Currently, low- and middle-income countries account for $>50 \%$ of lung cancer-related deaths annually (4). Many NSCLC patients are at an advanced stage at initial diagnosis due to its aggressive and early metastatic potential, thereby leading to a poor long-term prognosis. Thus, identification of effective strategies to predict and control NSCLC is essential.

Raf-1 proto-oncogene, serine/threonine kinase (Raf1) is an important part of the human RAS/RAF/MEK/ERK signaling pathway and is an important signaling molecule. Raf1 is closely associated with the regulation of cell proliferation and differentiation (5). Abnormal activation is found in many types of tumors and is mainly related to Rafl expression. An association between Raf1 and tumor invasion is found in prostate $(6)$, colorectal $(7,8)$ and thyroid cancer $(9)$.

We found that the prognosis of NSCLC after radiotherapy varies, even with the same stage and treatment. Raf1 plays a critical role in many types of tumors, but its expression and clinical significance remain to be reported in NSCLC primary tissues. Considering these findings, the present study aimed to determine the clinical value and prognostic significance of Raf1 in NSCLC patients following radiotherapy.

\section{Materials and methods}

Sample collection. In the present study, 110 samples of formalin-fixed paraffin-embedded NSCLC tissue were obtained between December 2011 and April 2014 from the Affiliated Jiangsu Cancer Hospital at the Nanjing Medical University in China. The tissue samples were collected from diagnosed patients by puncture or bronchoscopy biopsy. All cases were classified into the clinical types of NSCLC 
according to the American Joint Committee on Cancer (AJCC, 2010). All patients only received radiotherapy due to the financial concerns regarding targeted therapy and rejected other treatments.

Ethics statement. This study was approved by the Ethics Committee of Jiangsu Cancer Hospital. Written informed consent was obtained from all patients before treatment initiation.

Immunohistochemistry. Immunohistochemistry was performed using the standard streptavidin-peroxidase technique to determine Raf1 expression. Paraffin-embedded tissues were cut into 4- $\mu \mathrm{m}$ sections, dewaxed, and rehydrated using routine methods. All slides were subjected to heat-induced antigen retrieval using Tris buffer $(0.01 \mathrm{mmol} / \mathrm{l}, \mathrm{pH}, 6.0)$ in a pressure cooker. Then, the slides were placed in $3 \%$ hydrogen peroxide for $10 \mathrm{~min}$ to quench endogenous peroxidase. The sections were further incubated with anti-Raf1 (ab32025, GR176309-2; 1:1,000 dilution; Abcam, Hong Kong) overnight at $4^{\circ} \mathrm{C}$ after thoroughly rinsing thrice with phosphate-buffered saline (PBS) for $1 \mathrm{~min}$ each time. After washing in PBS, the sections were incubated with biotinylated secondary antibodies (Dako Denmark A/S, Glostrup, Denmark) for $30 \mathrm{~min}$ at room temperature and stained with freshly prepared 3,3'-diaminobenzidine and light hematoxylin as counterstain. Known positive controls were included in each staining procedure. PBS was used to replace primary antibodies in the negative control.

Immunohistochemical evaluation. Raf1 expression was quantified simultaneously by two independent observers who were blinded to the patient data. If the results of the two independent observers were different, then we would request for an additional pathology expert. In each case, four representative areas were selected, and $\geq 400$ tumor cells were observed at $x 400$ magnification. The percentage of positive cells was evaluated according to the number of positive cells divided by all cancer cells under a microscope at four selected foci. The following scale was adopted: 0 , no positive tumor cells; $1,1-10 \%$ positive tumor cells; 2, 11-50\%; and 3, 51-100\%. The staining intensity was evaluated by the presence of yellow- or brown-colored end product at the target antigen site. Furthermore, the staining intensity (no staining, mild, moderate, and intense) was graded as $0,1,2$, or 3 points, respectively $(0$, no detectable staining; 1, mild staining-light yellow; 2, moderate-yellow; and 3, intense-brown). Final scores were obtained by multiplying the positive tumor grade by the staining intensity score $(0,1,2,3$, 4, 6 and 9). The final scores $\leq 4$ and $\geq 6$ were considered tumors with low and high expression levels, respectively.

Cell culture. Human pulmonary carcinoma cell lines H1299 and A549 and transfected cell lines A549-7/Pb and A549-7/Raf1 were obtained from the Research Center of Clinical Oncology of the Affiliated Jiangsu Cancer Hospital, Nanjing Medical University, Nanjing, China and maintained in Dulbecco's modified Eagle's medium (DMEM) (Corning, Manassas, VA, USA) containing 10\% fetal bovine serum (FBS) (Gibco; Thermo Fisher Scientific, Inc., Waltham, MA, USA USA). Cultures were grown at $37^{\circ} \mathrm{C}$ in an atmosphere with $5 \% \mathrm{CO}_{2}$.
Cell lines A549-7/Pb and A549-7/Raf1 were established with transfected $\mathrm{Pb}$-puro empty vector and $\mathrm{Pb}$-puro-Raf1 plasmid using Lipofectamine 2000 reagent (Invitrogen; Thermo Fisher Scientific, Inc.), respectively.

Cell transfection. Raf1-siRNA and NC-siRNA were purchased from RiboBio (Guangzhou, China). The Lipofectamine 2000 transfection reagent was used to transfect the H1299 cell lines according to the manufacturer's instructions.

Western blot assay. Cells transfected after $48 \mathrm{~h}$ were extracted and prepared in RIPA buffer (Beyotime, Shanghai, China). BCA protein assay kit (Beyotime) was used to detect the protein concentration. The primary antibodies were purchased from Cell Signaling Technology, Inc. (Danvers, MA, USA USA). The anti-Raf 1 was obtained from Abcam. $\beta$-actin was used as the loading control. Immunoreactive bands were measured with ECL detection reagent (Millipore, Billerica, MA, USA).

$R N A$ isolation using quantitative $R T-P C$ reaction ( $q R T-P C R$ ). Fold changes for Raf $1 / \beta$-actin expression levels were calculated using the $2^{-\Delta \Delta \mathrm{Ct}}$ method. The total RNA from cells was extracted with TRIzol (Invitrogen; Thermo Fisher Scientific, Inc.). The PrimeScript First Strand cDNA Synthesis kit (Takara, Dalian, China) was used to synthesize first-strand cDNA. The SYBR-Green qRT-PCR was performed on an ABI7300 real-time PCR system (Applied Biosystems; Thermo Fisher Scientific, Inc.). The primer pairs were 5'-GGG AGCTTGGAAGACGATCAG-3' and 5'-ACACGGATAGTG TTGCTTGTC-3' for Raf1 and 5'-TTCTACAATGAGCTG CGTCTG-3' and 5'-CAGCCTGGATAGCAACGTATC-3' for $\beta$-actin. Each experiment was performed in triplicate.

Wound healing assay. Approximately $1.5 \times 10^{5}$ cells were plated in 6-well dishes and subsequently transfected with siRNA. An incision was created at the center of the cell monolayer as an artificial wound. Images of the wound area were captured using an optical microscope (Olympus Corp, Tokyo, Japan) with a magnification of $\mathrm{x} 10036 \mathrm{~h}$ after injury.

Invasion assay. Cell invasion was measured using 24-well BD Matrigel Invasion Chambers (BD Biosciences, Franklin Lakes, NJ, USA) according to the manufacturer's instructions. The A549 and H1299 cells were seeded into the upper well of the invasion chamber resuspended $\left(1.5 \times 10^{4}\right.$ cells per well) in $200 \mu 1$ serum-free medium after transfection. The lower chamber well containing $500 \mu \mathrm{l}$ DMEM and 20\% FBS was used to stimulate invasion. After $36 \mathrm{~h}$ of incubation, the invading cells were fixed with $4 \%$ paraformaldehyde and subsequently stained with crystal violet, whereas non-invading cells were removed. Cells were counted on optical microscope in $\mathrm{x} 40$ magnification fields.

Statistical analysis. All statistical analyses were conducted using SPSS 17.0 software (SPSS, Inc., Chicago, IL, USA). Overall survival (OS) was defined as the interval between the date of definite diagnosis and the date of death or last follow-up. Progression-free survival was defined as the time between the date of first recurrence and the last follow-up. The relationships between Raf1 and clinicopathological parameters 
Table I. Clinicopathological characteristics of 110 non-small cell lung cancer patients.

\begin{tabular}{|c|c|c|c|c|c|}
\hline \multirow[b]{2}{*}{ Clinical parameter } & \multirow[b]{2}{*}{ No. of cases } & \multicolumn{3}{|c|}{ Raf1 } & \multirow[b]{2}{*}{ P-value } \\
\hline & & Negative & Low & High & \\
\hline Sex & & & & & 0.995 \\
\hline Male & 67 & 37 & 17 & 13 & \\
\hline Female & 43 & 24 & 11 & 8 & \\
\hline Age (years) & & & & & 0.740 \\
\hline$\leq 70$ & 31 & 19 & 7 & 5 & \\
\hline$>70$ & 79 & 42 & 21 & 16 & \\
\hline Smoking status & & & & & 0.955 \\
\hline Non-smoker & 69 & 39 & 17 & 13 & \\
\hline Smoker & 41 & 22 & 11 & 8 & \\
\hline Lesion & & & & & 0.837 \\
\hline Peripheral & 78 & 42 & 21 & 15 & \\
\hline Central & 32 & 19 & 7 & 6 & \\
\hline Histology & & & & & 0.437 \\
\hline SQCC & 78 & 43 & 16 & 13 & \\
\hline $\mathrm{ADC}$ & 32 & 18 & 12 & 8 & \\
\hline Differentiation & & & & & 0.029 \\
\hline Moderate & 71 & 46 & 14 & 11 & \\
\hline Poor & 39 & 15 & 14 & 10 & \\
\hline $\mathrm{N}$ stage & & & & & 0.014 \\
\hline $\mathrm{cNO}$ & 68 & 45 & 14 & 9 & \\
\hline $\mathrm{cN} 1 / \mathrm{N} 2$ & 42 & 16 & 14 & 12 & \\
\hline T stage & & & & & 0.038 \\
\hline $\mathrm{T} 1$ & 22 & 16 & 4 & 2 & \\
\hline $\mathrm{T} 2$ & 53 & 33 & 11 & 9 & \\
\hline T3-4 & 35 & 12 & 13 & 10 & \\
\hline Radiotherapy & & & & & 0.074 \\
\hline CR & 45 & 31 & 9 & 4 & \\
\hline PR & 40 & 20 & 10 & 10 & \\
\hline SD & 25 & 10 & 9 & 7 & \\
\hline
\end{tabular}

SQCC, squamous cell carcinoma; ADC, adenocarcinoma; CR, complete response; PR, partial response; SD, stable disease.

were analyzed using the Chi-square test. For survival data, Kaplan-Meier curves were generated, and analysis was performed using the log-rank test. A prognostic analysis was performed using the univariate and multivariate Cox regression models. $\mathrm{P}<0.05$ was considered statistically significant.

\section{Results}

Protein expression of Rafl in NSCLC. Immunohistochemical staining of Raf1 was performed in 110 samples of primary NSCLC. Raf1 immunoreactivity was predominantly detected in the membrane, although weak cytoplasmic staining was observed. A total of $21(19.1 \%)$ and $28(25.5 \%)$ of the 110 samples exhibited high and low Raf1 expression levels, correspondingly. In addition, 61 (54.6\%) of the 110 specimens were assumed to have no staining (intensity score 0) (Table I and Fig. 1).
Correlations between Rafl expression and clinicopathological parameters. The clinicopathological characteristics of the patients are summarized in Table I. The immunohistochemical analyses of NSCLC tissues showed that Raf1 protein expression was significantly correlated with lymph node metastasis and $\mathrm{T}$ stage and was associated with poor histological differentiation ( $\mathrm{P}=0.014,0.038$ and 0.029 , respectively). However, no significant correlations were observed between Raf1 expression and age, gender, smoking status, tumor location, and lesion $(\mathrm{P}>0.05)$.

Univariate and multivariate analyses of prognostic factors. We analyzed the effect of Raf 1 expression on clinical outcomes in these patients. According to the univariate analysis (Table II), histological differentiation $(\mathrm{P}<0.05$ and $\mathrm{P}<0.05)$, T stage $(\mathrm{P}<0.05$ and $\mathrm{P}<0.05)$, lymph node metastasis $(\mathrm{P}<0.05$ and $\mathrm{P}<0.05)$, and Raf1 expression $(\mathrm{P}<0.05$ and $\mathrm{P}<0.05)$ were 
Table II. Univariate prognostic factor analyses for various clinical endpoints.

\begin{tabular}{|c|c|c|c|c|c|}
\hline \multirow[b]{2}{*}{ Factor } & \multirow[b]{2}{*}{$\mathrm{N}$} & \multicolumn{2}{|c|}{ TTP } & \multicolumn{2}{|c|}{ OS } \\
\hline & & (Median, M) & P-value & $\%$ (3-year) & P-value \\
\hline Sex & & & 0.734 & & 0.689 \\
\hline Male & 67 & 11 & & 9.8 & \\
\hline Female & 43 & 12 & & 27.9 & \\
\hline Age (years) & & & 0.642 & & 0.536 \\
\hline$\leq 70$ & 31 & 14 & & 10.1 & \\
\hline$>70$ & 79 & 11 & & 15.0 & \\
\hline Smoking status & & & 0.600 & & 0.537 \\
\hline Non-smoker & 69 & 12 & & 15.0 & \\
\hline Smoker & 41 & 10 & & 10.9 & \\
\hline Lesion & & & 0.194 & & 0.655 \\
\hline Peripheral & 78 & 11 & & 14.1 & \\
\hline Central & 32 & 13 & & 12.5 & \\
\hline Histology & & & 0.651 & & 0.680 \\
\hline SQCC & 72 & 10 & & 15.2 & \\
\hline $\mathrm{ADC}$ & 38 & 11 & & 13.7 & \\
\hline Differentation & & & 0.000 & & 0.000 \\
\hline Mederate & 71 & 14 & & 52.1 & \\
\hline Poor & 39 & 7 & & 32.4 & \\
\hline $\mathrm{N}$ stage & & & 0.000 & & 0.000 \\
\hline cNO & 68 & 14 & & 47.9 & \\
\hline $\mathrm{cN} 1 / \mathrm{N} 2$ & 42 & 9 & & 22.7 & \\
\hline T stage & & & 0.000 & & 0.000 \\
\hline $\mathrm{T} 1$ & 22 & 27 & & 44.4 & \\
\hline $\mathrm{T} 2$ & 53 & 13 & & 35.1 & \\
\hline T3-4 & 35 & 8 & & 27.0 & \\
\hline Radiotherapy & & & 0.000 & & 0.000 \\
\hline $\mathrm{CR}$ & 45 & 16 & & 22.0 & \\
\hline PR & 40 & 11 & & 10.0 & \\
\hline SD & 25 & 7 & & 0.3 & \\
\hline Raf1 & & & 0.002 & & 0.009 \\
\hline Negative or low & 89 & 13 & & 10.9 & \\
\hline High & 21 & 8 & & 0.1 & \\
\hline
\end{tabular}

TTP, time to progression; OS, overall survival; M, months; Y, years; SQCC, squamous cell carcinoma; ADC, adenocarcinoma; CR, complete response; PR, partial response; $\mathrm{SD}$, stable disease.
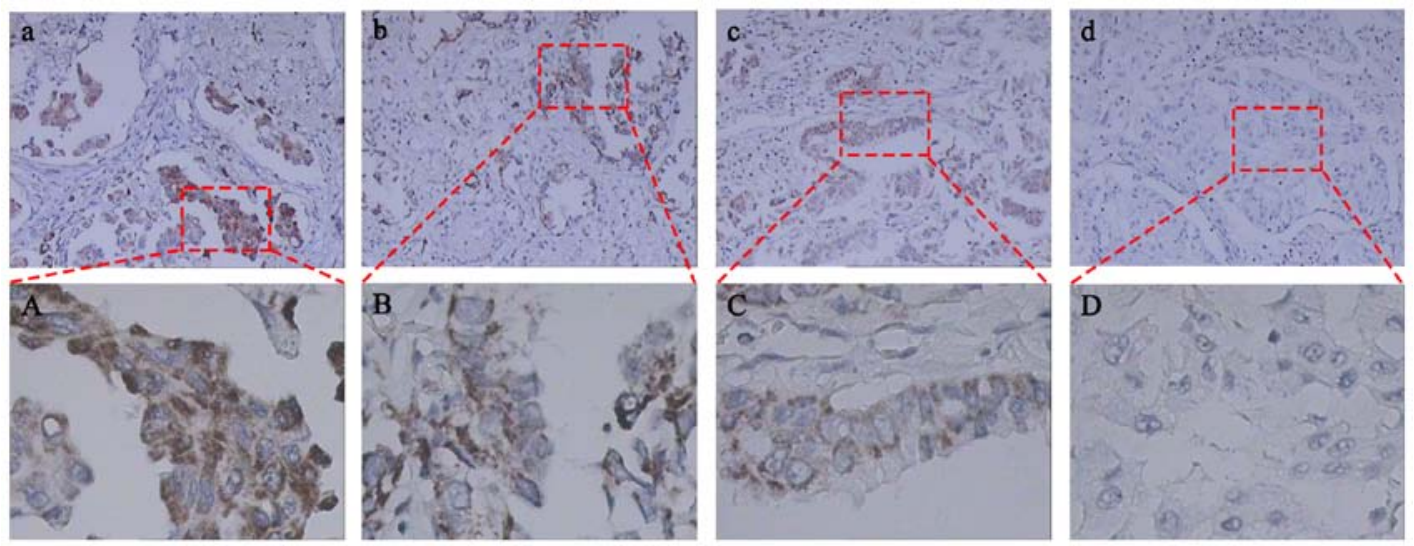

Figure 1. Immunohistochemical expression of Raf1 in human primary non-small cell lung cancer tissues. Raf1 protein was mainly expressed in the membrane with high (a), moderate (b), mild (c), and negative (d) expression levels with brownish-yellow staining. Images (a, b, c, and d) show high-power fields of the boxed areas in (A, B, C and D), respectively. Significantly increased Raf1 expression was detected in lung adenocarcinoma cells. (a-d), magnification x100; (A-D), magnification $\times 400$. 
Table III. Multivariable prognostic factor analyses for various clinical endpoints.

\begin{tabular}{lccccccr}
\hline & \multicolumn{3}{c}{ TTP } & & \multicolumn{2}{c}{ OS } \\
\cline { 2 - 3 } Factor & HR & $95 \% \mathrm{CI}$ & P-value & & HR & 95\% CI & P-value \\
\hline Differentation & 4.02 & $2.35-6.85$ & 0.00 & & 2.83 & $1.70-4.72$ & 0.00 \\
N stage & 1.35 & $0.85-2.16$ & 0.20 & & 1.24 & $0.77-1.99$ & 0.38 \\
T stage & 2.63 & $1.78-3.87$ & 0.00 & & 2.19 & $1.52-3.16$ & 0.00 \\
Radiotherapy & 1.80 & $1.32-2.47$ & 0.00 & & 1.40 & $1.04-1.88$ & 0.03 \\
Raf1 expression & 1.94 & $1.16-3.25$ & 0.01 & & 1.64 & $0.98-2.75$ & 0.06 \\
\hline
\end{tabular}

TTP, time to progression; OS, overall survival; HR, hazard ratio; CI, confidence interval.
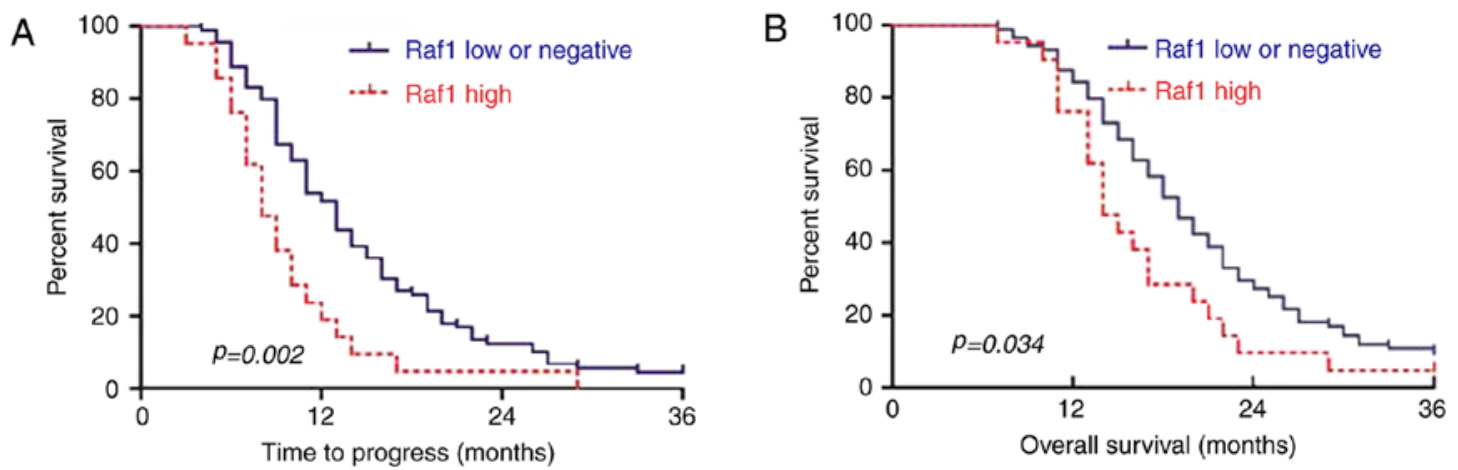

Figure 2. Survival curves of 110 patients with lung NSCLC after radiotherapy. (A) TTP and (B) 3-year survival time of patients with Raf1 high expression displayed a worse outcome compared with the patients with low or negative expression after radiotherapy (log-rank test, $\mathrm{P}=0.002$ and $\mathrm{P}=0.034)$, respectively. P-value was analyzed by the log-rank test. TTP, time to progression.
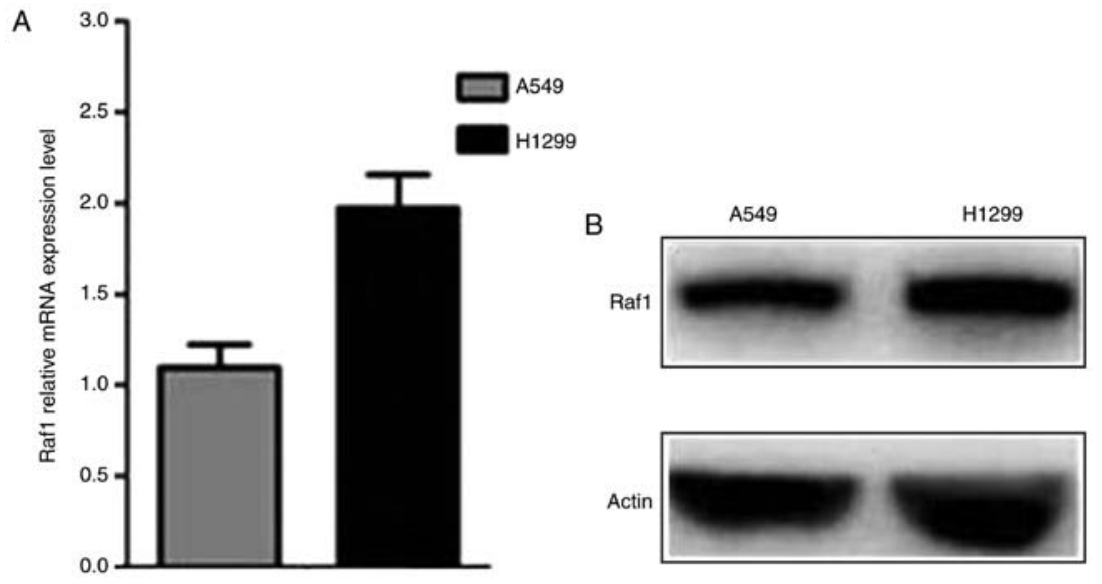

Figure 3. Raf1 expression in lung cancer cell lines with different metastatic potential. (A) Relative Raf1 mRNA expression in lung cell lines A549 and H1299. (B) Relative Raf1 protein levels in lung cell lines A549 and H1299. Data showed that Raf1 exhibited a relatively high expression in the highly metastatic potential lung cancer cell line H1299 but relatively low in the lower metastatic potential lung cancer cell line A549.

significantly associated with time to progression (TTP) and OS. The prognoses obtained were better in patients with Raf1-negative expression than in patients with positive expression. Abnormal Raf1 expression was associated with disease progression in patients with NSCLC. In the multivariate analysis (Table III), Raf1 expression was an independent risk factor for TTP (HR, 1.94, 95\% CI 1.16-3.25, $\mathrm{P}=0.01)$ and OS (HR, 1.64, 95\% CI 0.98-2.75, P=0.06). Survival curves showed that the TTP was earlier in the Raf1 low and negative group than in the high group $(\mathrm{P}=0.002)$. Moreover, the cumulative 3 -year survival rate was higher in the Raf1 low and negative group than in the high group $(\mathrm{P}=0.034)$ (Fig. 2). These data showed that Raf1 overexpression may lead to early TTP in patients with NSCLC after radiotherapy.

We selected the poor and strong metastatic capabilities of lung cancer cell lines A549 and H1299 to further investigate the prognostic value of Raf1 in NSCLC after radiotherapy. The relationship between Raf1 expression and the proliferation and 
A
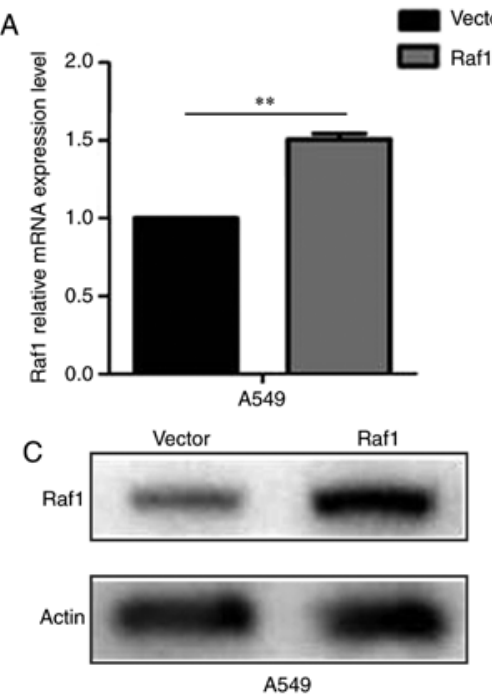

B

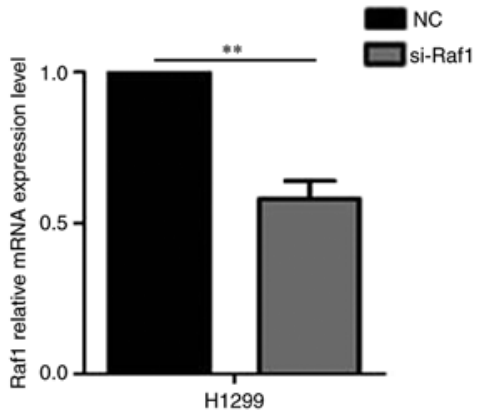

D
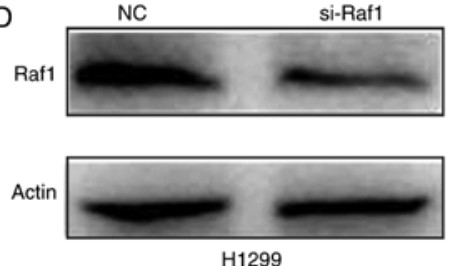

Figure 4. Raf1 expression in lung cancer cell lines A549 and H1299 after transfection. (A and C) Raf1 expression was increased in the A549 cells compared with the vector control. (B and D) Raf1 expression was decreased in the H1299 cells compared with the negative control (NC). Error bars represent the mean $\pm \mathrm{SD}$ of three independent experiments, ${ }^{* *} \mathrm{P}<0.05$.

invasion of lung cancer cells was also studied by the following methods.

Rafl expression in lung cancer A549 and H1299 cells. The qRT-PCR and western blot assay were conducted to determine the Raf1 expression in pulmonary carcinoma cell lines. The results showed that Raf1 was expressed in both cell lines and was higher in H1299 cells than in A549 cells (Fig. 3). The Raf1 expression in A549 and H1299 cells were upregulated and downregulated, respectively, after being transfected (Fig. 4).

Rafl promotes pulmonary carcinoma cell invasion and migration. We performed a gain-of-function analysis in vitro to examine the effect of Raf 1 on the invasion and migration of pulmonary carcinoma cells. The wound healing assay showed that the lateral migration capability was increased in the Raf1overexpressing A549 cells and decreased in the Raf1-silenced H1299 cells (Fig. 5). Vertical migration capability with the same result was observed in the Transwell migration assay (Fig. 6). In the Transwell invasion assay, the invasion capability was enhanced in the Raf1-overexpressing A549 cells and decreased in the Raf1-silenced H1299 cells (Fig. 7). Collectively, these results suggest that Raf1 accelerated the migration and invasion of pulmonary carcinoma cells.

\section{Discussion}

In the present study, we examined the Raf 1 expression in NSCLC patients, analyzed the correlations between Raf1 expression and clinicopathological parameters and assessed the value of the Raf1 expression and predicted the prognosis in NSCLC patients with radiotherapy. The effect of Raf1 on the metastasis and invasion of lung cancer A549 and H1299 cells was also confirmed.

Raf1 is the main transmitter of cell growth and reproduction signal conversion (10). It guides the receptor signals from the cell membrane to the nucleus (11). Once activated, Raf1 phosphorylates and activates the RAF/MEK/ERK signaling pathway, which then regulates the cell cycle, proliferation, apoptosis, and migration (12-15). Extensive studies have shown that Raf1 is overexpressed in various types of cancers, and Raf1 plays important roles in conferring resistance to erlotinib in NSCLC cell lines (16), disease risk in oral squamous cell carcinoma (17) and osteosarcoma progression (18). Truncated Raf1 expression was found to confer resistance to mesenchymal-epithelial transition factor inhibition (19), and the Raf1/ERK tyrosine kinase pathway was found to be involved in regulating the gene expression of multidrug resistance protein in pancreatic cancer cells (20). The Raf1 gene is expressed in prostate cancer samples (6) and potential clinically actionable fusions in prostate cancer cases (21). Raf1 fusions have also been reported to stimulate a mitogen-activated kinase-like protein in pilocytic astrocytoma (22). Activated Raf1 can phosphorylate activated protein kinases MEK1 and MEK2, which consequently phosphorylate to activate the serine/threonine-specific protein kinases ERK1 and ERK2 (23); these protein kinases play an important role in controlling the gene expression involved in cell division, apoptosis, differentiation, and migration (24). In a transgenic mouse model, overexpression of Raf1 kinase was found to induce genetic events associated with dysplasia in a genetic model of lung cancer (25). These findings suggest that Raf1 may play a role in human malignancies.

Recent studies have shown that Raf1 is positively expressed in thyroid cancer compared with adjacent normal tissues (9). Raf1 signals were detected in 28 (15\%) of 186 Chinese prostate cancer samples. High Raf1 genomic copy ( $>2$ copies) was found to be correlated significantly with old age ( $>65$ years) and high baseline PSA ( $>50 \mathrm{ng} / \mathrm{ml}$ ) (6). In the present study, we determined the Raf1 expression in 110 NSCLC specimens. The percentage of Raf1-positive expression was 44.5\% (49/110), and the rates of high and low expression were $19.1 \%$ (21/110) and 25.5\% (28/110), respectively. The univariate analyses showed that Raf1 expression was significantly correlated with histological differentiation, lymph node metastasis, and $\mathrm{T}$ stage. The patients with Raf1 expression displayed early TTP and poor OS. The multivariate analyses showed that Raf1 was an independent risk factor for TTP in these patients, and Raf1 overexpression also played an 
A

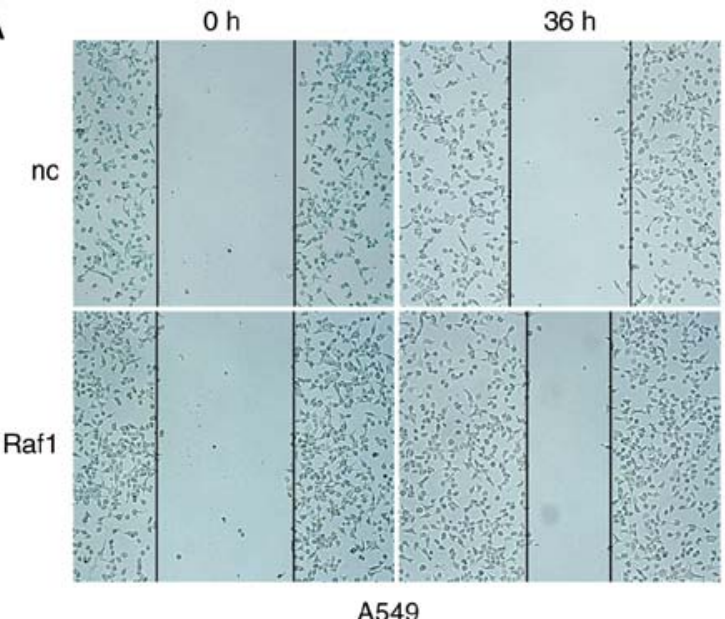

B

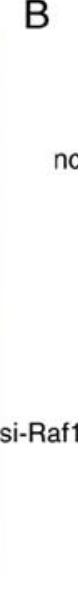

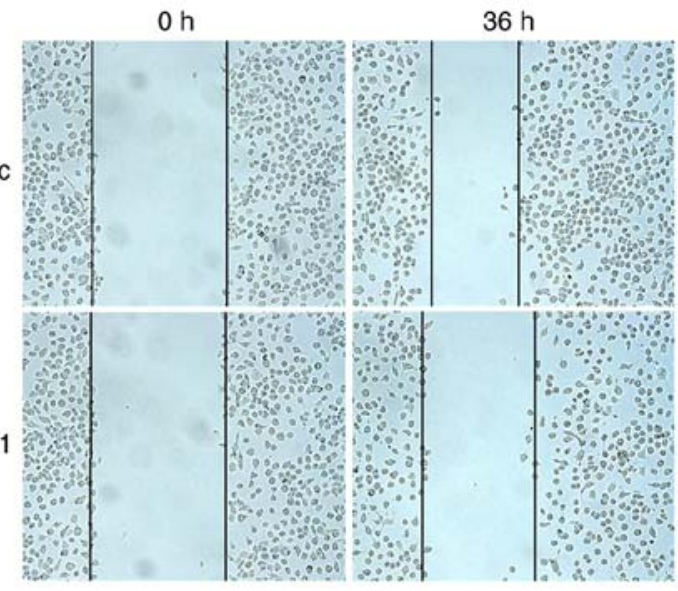

$\mathrm{H} 1299$

Figure 5. Wound healing assay showed that Raf1 expression affects the lateral migration in lung cancer cells. (A) Lateral migration capability was enhanced after the Raf1 expression was upregulated in lung cancer cells A549. (B) Lateral migration capability was decreased after the Raf1 expression was downregulated in lung cancer cell H1299. h, hour; nc, negative control.
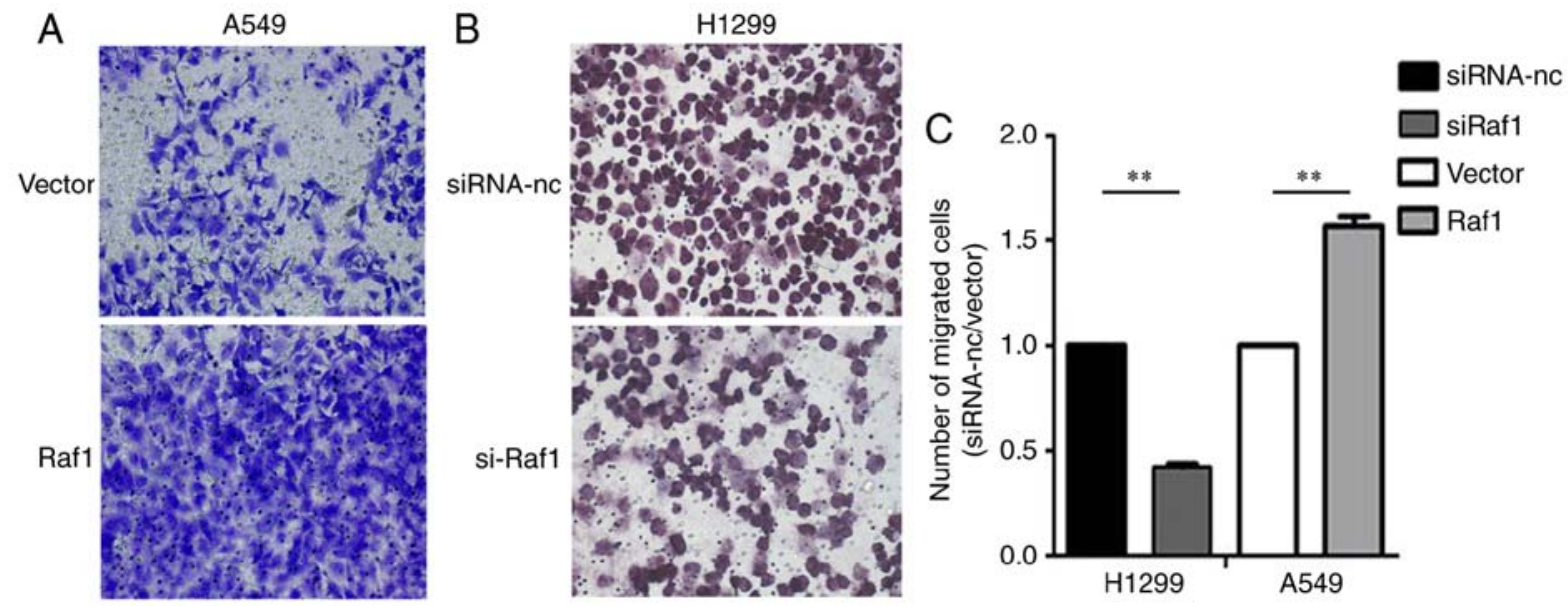

Figure 6. Transwell migration assay demonstrated that Raf1 expression affects the vertical migration in lung cancer cells. (A) Vertical migration capability was enhanced after Raf1 expression was upregulated in lung cancer A549 cells. (B) Vertical migration capability was decreased after Raf1 expression was downregulated in lung cancer H1299 cells. (C) High expression of Raf1 increased the number of migrated cells in lung cancer H1299 and A549 cells. Error bars represent the mean \pm SD of three independent experiments, ${ }^{* *} \mathrm{P}<0.01$.
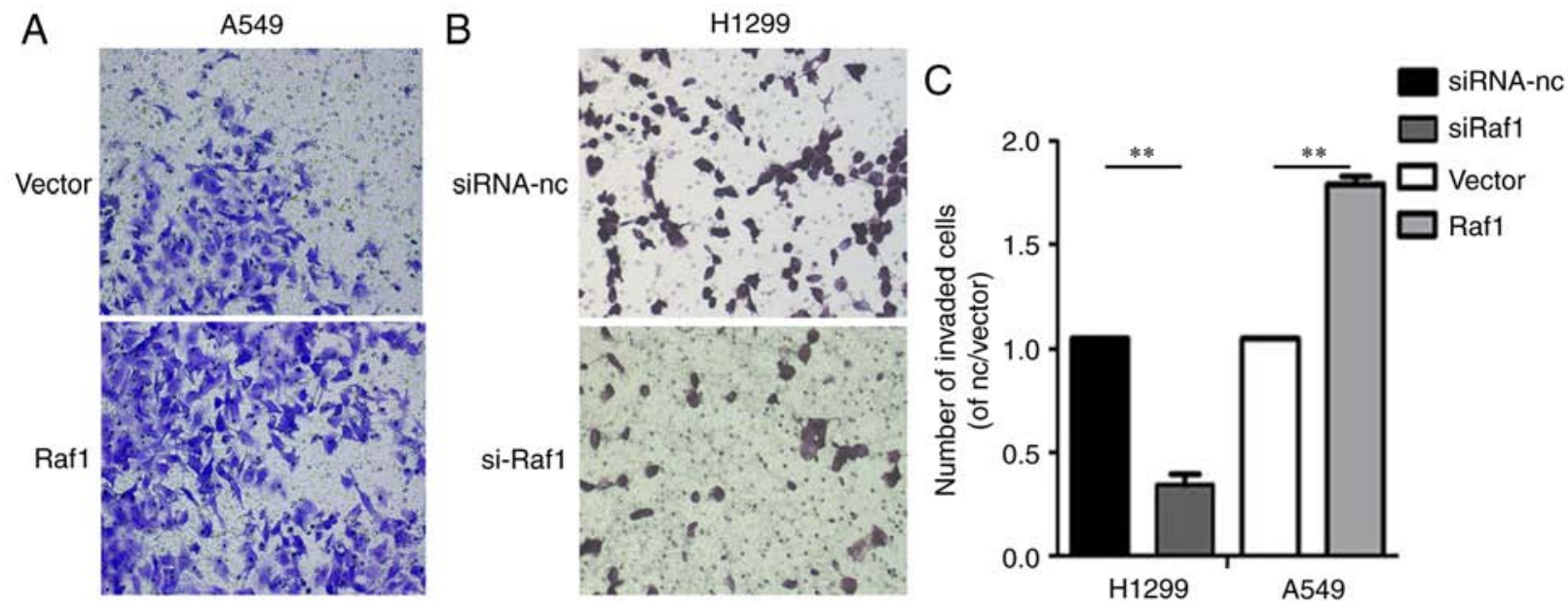

Figure 7. Transwell invasion assay shows that the Raf1 expression affects the invasion ability in lung cancer cells. (A) Invasion capability was enhanced after the Raf1 expression was upregulated in lung cancer A549 cells. (B) Invasion capability decreased after the Raf1 expression was downregulated in lung cancer H1299 cells. (C) High expression of Raf1 was increased the number of invaded cells in lung cancer H1299 and A549 cells. Error bars represent the mean \pm SD of three independent experiments, ${ }^{* *} \mathrm{P}<0.01$. 
important role in a poor 3-year OS compared with the patients with low and negative Raf1 expression. Yet, the difference was statistically insignificant $(\mathrm{P}=0.06)$. Significant results may have been obtained if the follow-up period was extended or the number of patients was increased. Furthermore, pcDNA3.1-Raf1 and Raf1-siRNA were used to transfect the A549 and H1299 cell lines, respectively, to further confirm the evidence linking Raf1 expression with metastasis or NSCLC recurrence. The wound healing and Transwell assays showed that Raf1 high-expressing cells showed strong invasion and migration capabilites when compared with the low expressing A549 and H1299 cells. These results agree partially with the findings that Raf1 is associated with cancer cell proliferation and invasion in pancreatic and colorectal cancer types $(20,26)$. Studies have also shown that histone deacetylase inhibitors through transcriptional downregulation of Raf1 suppressed c-Jun/Fra-1-mediated proliferation in neuroblastoma cells (27). Blocking Raf1 expression with microRNAs was found to inhibit the proliferation and invasion of thyroid and colorectal cancer types $(9,28)$. The molecular mechanisms related to the participation of Raf1 in the invasive process in NSCLC remain elusive. Therefore, further studies are required to clarify these mechanisms.

In conclusion, our results demonstrated that the high level of Raf1 expression in NSCLC tissue samples was associated with an early TTP and an adverse prognosis in patients with NSCLC. Raf1 expression was positively correlated with the invasion and migration capabilities of lung cancer A549 and H1299 cells.

\section{Acknowledgements}

The authors would like to thank the members of the Department of Pathology and the Research Center of Clinical Oncology, The Affiliated Jiangsu Cancer Hospital of Nanjing Medical University for providing the paraffin-embedded biopsies and technical assistance, respectively.

\section{Funding}

No funding was received.

\section{Availability of data and materials}

All data generated or analysed during this study are included in this published article.

\section{Authors' contributions}

$\mathrm{XH}$ and HT conceived and designed the experiments. HT performed the experiments. JZW and LY coordinated the research and analyzed the data. HT and LY wrote the manuscript. KD, XHW and YYX supported the experiments and helped to draft the manuscript. JZW provided the financial support and supervised laboratorial processes. All authors read and approved the final manuscript.

\section{Ethics approval and consent to participate}

This study was approved by the Ethics Committee of Jiangsu Cancer Hospital. Written informed consent was obtained from all patients before treatment initiation.

\section{Consent for publication}

Not applicable.

\section{Competing interests}

The authors declare that they have no competing interests.

\section{References}

1. Jemal A, Bray F, Center MM, Ferlay J, Ward E and Forman D: Global cancer statistics. CA Cancer J Clin 61: 69-90, 2011.

2. Ettinger DS, Akerley W, Borghaei H, Chang AC, Cheney RT, Chirieac LR, D'Amico TA, Demmy TL, Ganti AK, Govindan R, et al: Non-small cell lung cancer. J Natl Compr Canc Netw 10: 1236-1271, 2012

3. Siegel RL, Miller KD and Jemal A: Cancer statistics. CA Cancer J Clin 66: 7-30, 2016.

4. Torre LA, Siegel RL and Jemal A: Lung Cancer statistics. Adv Exp Med Biol 893: 1-19, 2016.

5. Cobb MH, Hepler JE, Cheng $M$ and Robbins D: The mitogen-activated protein kinases, ERK1 and ERK2. Semin Cancer Biol 5: 261-268, 1994.

6. Ren G, Liu X, Mao X, Zhang Y, Stankiewicz E, Hylands L, Song R, Berney DM, Clark J, Cooper C and Lu YJ: Identification of frequent BRAF copy number gain and alterations of RAF genes in Chinese prostate cancer. Genes Chromosomes Cancer 51: 1014-1023, 2012.

7. Slattery ML, Lundgreen A and Wolff RK: MAP kinase genes and colon and rectal cancer. Carcinogenesis 33: 2398-2408, 2012.

8. Borovski T, Vellinga TT, Laoukili J, Santo EE, Fatrai S, van Schelven S, Verheem A, Marvin DL, Ubink I, Borel Rinkes IHM and Kranenburg O: Inhibition of RAF1 kinase activity restores apicobasal polarity and impairs tumour growth in human colorectal cancer. Gut 66: 1106-1115, 2017.

9. Wang F, Jiang C, Sun Q, Yan F, Wang L, Fu Z, Liu T and Hu F: miR-195 is a key regulator of raf1 in thyroid cancer. Onco Targets Ther 8: 3021-3028, 2015.

10. Wellbrock $\mathrm{C}$, Karasarides $\mathrm{M}$ and Marais R: The RAF proteins take centre stage. Nat Rev Mol Cell Biol 5: 875-885, 2004.

11. McKay MM and Morrison DK: Integrating signals from RTKs to ERK/MAPK. Oncogene 26: 3113-3121, 2007.

12. McCubrey JA, Steelman LS, Chappell WH, Abrams SL, Wong EW, Chang F, Lehmann B, Terrian DM, Milella M Tafuri A, et al: Roles of the Raf/MEK/ERK pathway in cell growth, malignant transformation and drug resistance. Biochim Biophys Acta 1773: 1263-1284, 2007.

13. Steelman LS, Chappell WH, Abrams SL, Kempf RC, Long J, Laidler P, Mijatovic S, Maksimovic-Ivanic D, Stivala F, Mazzarino MC, et al: Roles of the Raf/MEK/ERK and $\mathrm{PI} 3 \mathrm{~K} / \mathrm{PTEN} / \mathrm{Akt} / \mathrm{mTOR}$ pathways in controlling growth and sensitivity to therapy-implications for cancer and aging. Aging (Albany NY) 3: 192-222, 2011.

14. Hwang YH, Choi JY, Kim S, Chung ES, Kim T, Koh SS, Lee B, Bae SH, Kim J and Park YM: Over-expression of c-raf-1 proto-oncogene in liver cirrhosis and hepatocellular carcinoma. Hepatol Res 29: 113-121, 2004.

15. Kyriakis JM, App H, Zhang XF, Banerjee P, Brautigan DL, Rapp UR and Avruch J: Raf-1 activates MAP kinase-kinase. Nature 358: 417-421, 1992.

16. Xu ZH, Hang JB, Hu JA and Gao BL: RAF1-MEK1-ERK/AKT axis may confer NSCLC cell lines resistance to erlotinib. Int J Clin Exp Pathol 6: 1493-504, 2013.

17. Kordi-Tamandani DM, Saberi E, Jamali S and Ladiz MA: ERK and RAF1 gene: Analysis of methylation and expression profiles in patients with oral squamous cell carcinoma. Br J Biomed Sci 71: 100-103, 2014.

18. Chen L, Wang Q, Wang GD, Wang HS, Huang Y, Liu XM and Cai XH: Mir-16 inhibits cell proliferation by targeting IGF1R and the Raf1-MEK1/2-ERK1/2 pathway in osteosarcoma. FEBS Lett 587: 1366-1372, 2013.

19. Petti C, Picco G, Martelli ML, Trisolini E, Bucci E, Perera T, Isella $\mathrm{C}$ and Medico E: Truncated RAF kinases drive resistance to MET inhibition in MET-addicted cancer cells. Oncotarget 6: 221-233, 2015. 
20. Xiao Z, Ding N, Xiao G, Wang S, Wu Y and Tang L: Reversal of multidrug resistance by gefitinib via RAF1/ERK pathway in pancreatic cancer cell line. Anat Rec (Hoboken) 295: 2122-2128, 2012.

21. Robinson D, Van Allen EM, Wu YM, Schultz N, Lonigro RJ, Mosquera JM, Montgomery B, Taplin ME, Pritchard CC and Attard G: Integrative clinical genomics of advanced prostate cancer. Cell 161: 1215-1228, 2015.

22. Lawson AR, Tatevossian RG, Phipps KP, Picker SR, Michalski A, Sheer D, Jacques TS and Forshew T: RAF gene fusions are specific to pilocytic astrocytoma in a broad paediatric brain tumour cohort. Acta Neuropathol 120: 271-273, 2010.

23. Brennan DF, Dar AC, Hertz NT, Chao WC, Burlingame AL, Shokat KM and Barford D: A Raf-induced allosteric transition of KSR stimulates phosphorylation of MEK. Nature 472: 366-369, 2011.

24. Li P, Wood K, Mamon H, Haser W and Roberts T: Raf-1: A kinase currently without a cause but not lacking in effects. Cell 64: 479-482, 1991.
25. Rohrbeck A, Müller VS and Borlak J: Molecular characterization of lung dysplasia induced by c-Raf-1. PLoS One 4: e5637, 2009.

26. Li X, Stevens PD, Liu J, Yang H, Wang W, Wang C, Zeng Z, Schmidt MD, Yang M, Lee EY and Gao T: PHLPP is a negative regulator of RAF1, which reduces colorectal cancer cell motility and prevents tumor progression in mice. Gastroenterology 146: 1301-1312, 2014.

27. He W, Wu Y, Tang X, Xia Y, He G, Min Z, Li C, Xiong S, Shi Z, Lu Y and YuanZ: HDAC inhibitors suppress c-Jun/Fra-1-mediated proliferation through transcriptionally downregulating MKK7 and Raf1 in neuroblastoma cells. Oncotarget 7: 6727-6747, 2016.

28. Chai J, Wang S, Han D, Dong W, Xie C and Guo H: MicroRNA-455 inhibits proliferation and invasion of colorectal cancer by targeting RAF proto-oncogene serine/threonine-protein kinase. Tumour Biol 36: 1313-1321, 2015. 